\begin{tabular}{|c|c|}
\hline Title & Preferences, beliefs, and heuristics \\
\hline Author(s) & Yamagishi, Toshio \\
\hline Citation & Behavioral and Brain Sciences, 28(6), 836-837 \\
\hline Issue Date & 2005 \\
\hline DOC URL & http:/hdl.handle.net/2115/1437 \\
\hline Type & article (author version) \\
\hline Note & $\begin{array}{l}\text { Open peer commentary for:“" Economic man” in cross cultural perspective: Behavioral experiments in } 15 \text { small-scale } \\
\text { societies, BEHA V IORA L AND BRA IN SCIENCES (2005) 28, 795-855 Copyright } \odot 2005 \text { Cambridge University } \\
\text { Press }\end{array}$ \\
\hline Note(URL) & http://ournal s.cambridge.org/action/display I ssue?sort_by=display_order\&jid=BBS\& volumel d=28\& issuel d=06 \\
\hline File Information & BBS28-6.pdf \\
\hline
\end{tabular}

Instructions for use 


\title{
Preferences, beliefs, and heuristics
}

\author{
Toshio Yamagishi
}

Graduate School of Letters, Hokkaido University, Sapporo, Japan 060-0810.

Toshio@let.hokudai.ac.jp

http://lynx.let.hokudai.ac.jp/members/yamagishi/

\begin{abstract}
Alternative interpretations are proposed for the finding that market integration is positively related to fair behavior in experimental games. Market activities may produce market relevant concepts and stories that interpret experimental games as incidences of social exchange, and thus may enhance the relevance of (1) market-related preferences or (2) a decision heuristic designed for social exchange.
\end{abstract}

The findings coming out of the cross-cultural experiment conducted by Henrich and his collaborators are of extreme importance for those economists who are starting to reconsider the super "rational" view of economic man, as well as for social scientists already aware of the social and cultural malleability of human behavior. Among the many interesting findings reported in the study, my comments focus mainly on the discovery that college students in industrial societies are less "rational" in their decision-making compared to people living in small societies lacking a modern market economy. This finding must be surprising for those who believe that people living in industrial societies are more "individualistic" - putting self-interest ahead of the collective interest - than people who are less involved with a market economy. Surprising and counter-intuitive findings often fuel new advances in science, and therefore I admire the authors for providing us with this important insight.

Nevertheless, interpreting this finding will certainly kindle a great deal of controversy. The authors adopt a “preferences, beliefs, and constraints approach" (sect. 9, para. 2) in interpreting their results, according to which "agents maximize a preference function subject to informational and material constraints" (sect. 9, para. 2, emphasis in original). They further argue that humans "acquire the beliefs and preferences appropriate for the local social environment” (sect. 9, para. 4). These are very general statements, and there is more than one manner in which these principles are applied for interpreting the findings. I propose three plausible alternatives for the authors' consideration.

Preferences are different. The most straightforward interpretation of the finding, which I believe is the closest to the authors' position, is that people acquire different preferences in different societies. In particular, people who have been exposed to a market economy acquire a preference for fairness and reciprocity, presumably because such a preference would assist exchange in market-based societies by ensuring proper behavior. This interpretation seems to provide a decent description of the findings, but faces a challenge when explaining why market exposure works at the group level but not at the individual level. Gains associated with market-relevant preferences should predominantly work at the individual level. There may be an aggregation effect of individual dispositions, but this should not eliminate the effect of individual exposure to 
market activities.

Sensitivity to cues that suggest the experimental situation is a form of social exchange. The second explanation is more compatible with the group level effect of exposure to a market environment. In societies and communities that are widely exposed to market activities, the stories people use in describing their own and others' behavior may involve market-relevant concepts. Such stories and the way people talk about their activities cannot be confined to a particular individual; they have to be shared by community members if they are to make any sense at all. Cultural beliefs and stories are fundamentally a group level phenomenon. Once people begin using market-relevant vocabulary, they become sensitive to cues of fairness and reciprocity that suggest an activity is market related. Hence, they should be quicker to perceive the abstract rules of the experimental game as a form of social exchange. According to this interpretation, preferences are not necessary to explain differences in behavior; two people in an experimental game could make different decisions if one perceives the game as a form of social exchange and the other does not, even if they are given the same information beforehand and share an identical preference for fairness.

The activation of heuristics. The third interpretation is similar to the second in that it emphasizes the importance of cues connecting experimental games to relevant forms of social exchange. However, it is different from the second in that cues activate heuristics rather than the perception of relevance of particular preferences. In psychology, a number of dual-process models have been applied to behavior (Chaiken 1980; Metcalfe \& Mischel 1999; Petty \& Cacioppo 1986; Pyszczynski \& Greenberg 1987; Zajonc 1980). According to these models, judgment and decisionmaking often involve two, separate but parallel information processes. One is fast, automatic, unconscious (i.e., does not require attention), and intuitive (heuristic decision-making), whereas the other is slow, intentional, conscious, and rational (reasoned decision- making). Either process can be used to make a decision, and different conclusions can be made by the two processes. If the decision involves serious consequences, and if sufficient attention is devoted, the reasoned process can supersede the heuristic process. However, because the heuristic process works faster, we often draw our conclusion before the reasoning process can catch up and, in many cases, reason is invoked simply to "justify" a decision that has already been made (Haidt 2001). The heuristic information process is often the default option, automatically operating without conscious allocation of attention. Assuming that the cues available in experimental games are likely to be interpreted as suggestive of social exchanges in market-based societies, one possible interpretation of the current finding is that a decision heuristic relevant to social exchange is activated during an experimental game, thereby enticing the participant to automatically behave more equitably (Kiyonari et al. 2000). It is likely that the cultural beliefs shared by traditional people do not sensitize them to market-relevant cues in experimental games and, consequently, they may not perceive experimental games as a form of social exchange. In the absence of proper heuristics to use in experimental games, people in communities with less or no market exposure are "forced" to use reasoned information processing and make "rational" decisions.

Although, personally, I believe this last interpretation to be the most plausible, this is 
ultimately an empirical matter. The challenge will be to design an experiment powerful enough to test the validity of these three alternatives. Some of the experimental techniques used by cognitive psychologists to assess how much information processing is involved in a particular decision task may beuseful in such an endeavor. 